a rule remain at a standstill, or grow gradually less, but increases, and is associated after a time with other phenomena of chronic Bright's disease, such as hypertrophy of left ventricle, odema, and high vascular tension. A. F.

\title{
STATUS EPILEPTICUS.
}

G. R. Trowbridge, M.D., and C. B. Mayberry, M.D., in The Journal of the American Medical Association, Nov. 7, I89I, draw the following conclusions from a paper on this subject: On account of its association with epilepsy, status epilepticus should not be considered as a distinct disease, but merely a climax of the neurosis. It consists of two stages: a convulsive and a comatose, though the latter is sometimes replaced by a period of maniacal excitement. That there is no demonstrable lesion causative of the status. That the prognosis is unfavorable. That the treatment is in a measure symptomatic, but considerable reliance can be placed upon the hypodermic use of the hydrobromates of hyoscine or conine, combined with morphine. A. F.

\section{FUNCTIONAL BRAIN DEGENERACY.}

J. T. Searcy, in The Journal of the American Medical Association, Nov. 7, r89r, says: Brain capacity is the result of ancestral and individual brain practice. The test of these qualifications are the grades of intellectual and ethical abilities, usually determined by the level the individual, the family, or the race occupies in competitive life. Degeneracies of brain ability are occasioned by brain inactivity, which is the principle method of deterioration; but whatever injures the brain structure impairs intellectual and ethical ability, whether it be traumatism, disease or defect, or abuse with drugs. A great field for the highest order of public sanitation is open in this direction, heretofore almost wholly unoccupied by our profession. A. F.

NEURALGIA FOLLOWING FRACTURE SUCCESSFULLY TREATED BY OPERATION.

Reginald H. Sayre, M.D., in the New York Medical Journal, Aug. 22, 189I, records the case of a young man who had small-pox when an infant, which apparently caused such a degree of fragility of right femur that it was broken in nearly the same place on three occasions, each four years from 
the other, and caused by slight violence. Persistent neuralgia followed the last fracture, and lasted for six ycars up to the time of operation, in spite of various treatmcnts. The relief of tension given by splitting up the fascia lata, which bound the muscles very tightly, was followed by cessation of pain, and as nearly three years have elapsed since the operation with no return of the neuralgia, Dr. Sayre believes the cure will be permanent.

A. F.

\section{ETIOLOGY OF ITLHING.}

According to Dr. E. B. Bronson (Medical Record, Oct. 24, I 89I), the primary cause of itching pertains to hidden molecular or dynamic changes within the sensory nervous apparatus, changes whose immediate effect has been presumed to be of the nature of a dysasthesia, and whose only ostensible sign is the perturbed sensation. The accessory pathological causes he tabulates as follows: Predisposing causes.- $A$ : A state of cutaneous hyperæsthesia, or excessive irritability of the cutaneous nerves. It may occur, (a) as the local expression of a general neurotic condition, congenital or acquired, in which case the simplest excitants, as friction of clothing, may evoke the sensation; or, (b) it may be due to local changes in the skin, attended with prolonged irritation of the cutaneous sensory nerves. A $B:$ state of hypopselaphesia, i.c., a state of impaired conduction in the cutaneous nerves of tactile sense. Though usually occurring as a concomitant of hyperæsthesia of the skin, it is possible that it may exist independently of the latter, as in atrophic conditions (more particularly in pruritus senilis), when, like hyperasthesia, it may become the predisposing cause of itching. Exciting causes.- $A$ : Irritations conveyed to the skin from the interior of the body, either as (a) reflex irritations; or as (b) irritations transmitted from nervous centres. $B$; Direct or local irritation, $(a)$ from extraneous sources, i.c., from such irritants as operate upon the surface of the skin; (b) from intra-cutaneous sources, comprising ( $I$ ) lesions of trophic cutaneous diseases and their products; (2) toxic materials deposited from the blood; (3) effects of local nutritive disturbances, or deranged metabolism in the cutaneous sensory nerves; (4) spastic contraction of the arrectores pilorum muscles, which, though it may not of itself suffice to cause itching, is probably often associated with other causes as a contributory factor. 